\title{
$\mathrm{DCM}$ 에서 $\mathrm{PV}$ 시스템용 부스트 컨버터의 개선된 제어방식 \\ 이영진 ${ }^{1}$, 한동화 ${ }^{1}$, 변병주 ${ }^{1}$, 최중묵 ${ }^{1}$, 바이스갈랑 ${ }^{1}$, 최규하 ${ }^{\dagger}$
}

\section{The Modified Control Method of Boost Converter for PV System in DCM}

\author{
Young-Jin Lee ${ }^{1}$, Dong-Hwa Han ${ }^{1}$, Byeong-Joo Byen ${ }^{1}$, Jung-Muk Choi ${ }^{1}$, \\ Dugarjav Bayasgalan ${ }^{1}$, and $\mathrm{Gyu}-\mathrm{Ha} \mathrm{Choe}^{\dagger}$
}

\begin{abstract}
This paper presents a improved control technique to overcome disadvantage when the inductor current of boost converter in PV system becomes DCM(Discontinuous Conduction Mode) due to the low insolation. MPPT(Maximum Power Point Tracking) output reference voltage could not be exactly followed by conventional dual-loop PI control method used typically because of the error between the actual current and measured current. Therefore, in this paper, Hybrid controller that changes the control method in DCM and $\mathrm{CCM}$ (Continuous Conduction Mode), and single state feedback controller are used to compensate that problem. The proposed control technique was verified by simulation using PSIM 9.0 and experiments.
\end{abstract}

Keywords: boost converter, hybrid controller, state feedback controller, discontinuous conduction mode

\section{1. 서 론}

최근 유가 강세가 지속되면서 국가 에너지 위기론이 재부상하고 있어, 미래 지향적인 측면으로 볼 때 정부차 원의 본격적인 태양광, 풍력발전 등의 신재생 에너지 개 발이 필수적인 상황이 되었다. 신재생에너지를 사용하는 방식은 독립형과 계통연계형 2가지로 분리 되며 독립형 발전시스템은 무인 중계소, 무인등대, 인공위성, 도서 및 산간지역등 전력공급이 원활하지 못한 지역의 특수 전 원용으로 다수 사용되고 있다. 계통 연계형 태양광 발전 시스템은 주택용 전원이나 대용량 발전소에 적용 가능 한 시스템으로, 발전 시스템의 출력이 부하가 요구하는 전력보다 클 경우 잉여전력을 계통에 공급하고, 반대로 시스템에서 발생되는 전력이 부하의 요구량보다 적은 경우에는 부족분을 계통으로부터 공급 받을 수 있다는 장점을 지닌다. ${ }^{[1]-[3]}$

PV-array에서 발생되는 출력은 주변 온도 및 일사량 에 따라서 비선형적 특성을 가지며 변동을 한다. 이러한 특성을 갖는 PV-array에서 최대출력을 얻기 위해서는

Paper number: TKPE-2013-18-4-1

ISSN: $1229-2214$

† Corresponding author: ghchoe@konkuk.ac.kr, Dept. of Electrical Eng., Konkuk University

Tel: +82-2-450-3496 Fax: +82-2-447-9186

${ }^{1}$ Dept. of Electrical Eng., Konkuk University

Manuscript received Jan. 16, 2013; accepted Mar. 26, 2013
MPPT(Maximum Power Point Tracking)알고리즘을 적 용하여 최대 출력이 발생하는 전압으로 $\mathrm{PV}-\mathrm{array}$ 의 출 력전압을 제어해야 한다. ${ }^{[4]}$ 최근 $10 \mathrm{~kW}$ 미만의 태양광 시스템은 그림 1 과 같이 저전압으로 발전된 $\mathrm{PV}-\mathrm{array}$ 의 출력을 인버터를 동작시킬 수 있는 최소한의 전압으로 승압시키는 부스트 컨버터와 승압된 $\mathrm{DC}$ 링크전압을 교 류로 변환시키는 계통연계형 인버터(PWM 인버터)로 구 성되는 2단방식이 많이 사용되고 있다. 일반적으로 사용 되는 계통연계형 $\mathrm{PV}$ 시스템의 제어는 부스트 컨버터에서 $\mathrm{MPPT}$ 제어를 수행하며, PWM 인버터에서 DC링크 전 압제어와 출력 전류제어를 수행한다. ${ }^{[5]}$

기존에 많이 사용되는 부스트 컨버터(Boost Converter) 의 제어방식은 전압제어기를 외부루프에 두고 전류제어 기를 내부루프에 배치하는 이중루프 PI 제어기이다. 하 지만 이렇게 제어기가 구성되면, 일사량이 적을 경우 부 스트 컨버터의 인덕터에 불연속 전류가 흐르게 되어서 실제 인덕터에 흐르는 전류와 전압제어기의 출력인 전 류 지령치에 오차가 발생하게 된다. ${ }^{[6]}$ 오차가 발생하는 원인은 전압제어기에서는 평균전류를 출력으로 내보내 고 있지만 DCM 구간에서 측정되는 실제 인덕터 전류는 불연속으로 인해 평균전류를 측정하지 못하기 때문이다. 이로 인하여 기존의 이중루프 제어방식을 태양광 발전 시스템에 사용하게 되면 $\mathrm{MPPT}$ 출력전압을 정확히 추 종하지 못하는 상황이 발생된다. 이러한 문제점을 고려 하여 $\mathrm{DCM}$ 구간에서 측정 포인트를 변경하는 방식 또는 
샘플링 된 전류피드백에 전향보상을 하여 측정오차를 제거하는 방식이 연구되어왔다. ${ }^{[6]}$ 본 논문에서는 기존의 방식과 달리 접근하여 불연속 구간에서 안정적인 입력 전압 제어특성을 갖는 제어방식에 대하여 연구하였다.

본 논문에서 제시하는 제어방식은 전류제어기를 생략 한 단일루프 상태궤환 제어기(State feedback controller) 와 인덕터 전류의 연속 및 불연속모드에서 전류제어기 의 구조를 바꾸는 복합 제어기(Hybrid controller)이며, 시뮬레이션 및 실험을 통해 타당성을 입증한다.

\section{2. 기존의 부스트 컨버터의 제어}

본 연구에서 사용된 태양광 발전시스템은 그림 1 과 같이 부스트 컨버터와 계통 연계형 인버터로 구성 되었 다. 계통연계형 인버터에서는 직류링크 전압제어와 출력 단 전류제어를 수행한다. ${ }^{[7]}$ 본 연구에서는 부스트 컨버 터의 제어방식만을 다루므로 계통 연계형 인버터의 제 어방식은 다루지 않는다.

기존의 부스트 컨버터의 제어기는 MPPT 알고리즘의 결과 생성되는 전압기준신호 $\left(v_{p v}^{*}\right)$ 를 추종하도록 전압 전 류 2중 루프로 구성 된다. 이중루프 제어의 경우 내부루 프로 전류 제어기를 사용하면 제어의 속응성이 좋아지 는 특성을 얻을 수 있다. ${ }^{[7]}$ 하지만 인덕터 전류가 불연 속이 될 경우 정확한 제어가 이루어지기 어렵다.

그림 2는 부스트 컨버터의 회로도 및 이중루프 제어 방식을 나타낸다. 이중루프 제어 및 본 연구에서 제안하 는 제어방식의 제어기 이득 값 선정을 위해서 부스트 컨버터의 전압 방정식 및 전류 방정식을 세우면 식(1) 식(3)과 같으며, 방정식은 이상적인 시스템임을 전제로 정리하였다.

$$
\begin{aligned}
& v_{p v}=L_{d c} \frac{d i_{p v}}{d t}+v_{s w} \\
& v_{s w}=(1-S w(t)) v_{d c o n}
\end{aligned}
$$

여기서, $S w(t)=\left\{\begin{array}{ll}1 & S w: \text { on } \\ 0 & S w: \text { off } f\end{array}\right.$ 컨버터의 스위칭함수

$$
C_{p v} \frac{d v_{p v}}{d t}=i_{s o l}-i_{p v}
$$

인덕터 전류 $i_{p v}$ 를 제어하기 위해 $\mathrm{PI}$ 제어기 $\left(K_{p i}, K_{i j}\right)$ 를 이용한 제어규칙을 다음 식 (4)와 같이 설정한다.

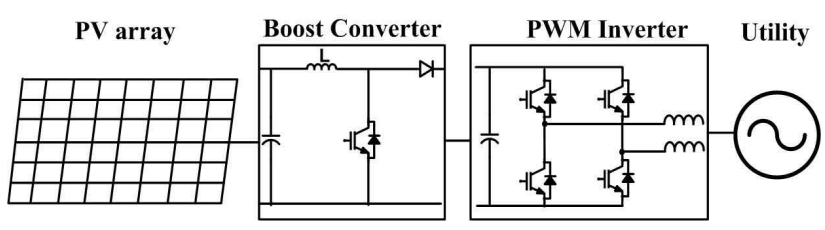

Fig. 1 Configuration of PV system $v_{s w}^{*}(t)=v_{p v}(t)-\left[k_{p i}\left(i_{p v}^{*}(t)-i_{p v}(t)\right)+k_{i i} \int\left(i_{p v}^{*}(t)-i_{p v}(t)\right) d t\right]$

한주기 스위칭 $\left(T_{m o d}\right)$ 시간 내에서 제어전압 $v_{s w}^{*}(t)$ 가 일 정하다고 가정하면 한주기 스위칭 구간에서 스위치 양 단전압 $v_{s w}(t)$ 의 평균치는 다음 식(5)와 같으므로,

$$
\frac{1}{T_{\bmod }} \int_{0}^{T_{\bmod }} v_{s w}(t) d t=\frac{T_{\text {off }}}{T_{\bmod }} v_{d c o n}=v_{s w}^{*}
$$

스위치 양단전압의 고조파 성분을 무시하고 다음과 같이 가정할 수 있다.

$$
v_{s w}^{*}=v_{s w}
$$

그러므로 식 (4)를 식 (1)에 대입하고 라플라스 변환 을 하면 다음과 같은 전달함수를 얻을 수 있으며, 영점 을 배제하고 극점에 의한 원형 2차 시스템의 설계법인 극배치 방법에 의해 아래와 같이 제어기 이득이 계산된 다. ${ }^{[8]}$

$$
\frac{i_{p v}(s)}{i_{p v}^{*}(s)}=\frac{\frac{K_{p i}}{L_{p v}} s+\frac{K_{i i}}{L_{p v}}}{s^{2}+\frac{K_{p i}}{L_{p v}} s+\frac{K_{i i}}{L_{p v}}}
$$

컨버터의 전압제어기는 MPPT에서 출력된 지령값 $\left(v_{p v}^{*}\right)$ 과 실제값 $\left(v_{p v}\right)$ 을 비교하고 이를 $\mathrm{PI}$ 제어기 $\left(K_{p v}\right.$ $\left.K_{i v}\right)$ 를 통해 컨버터의 전류기준신호 $\left(i_{p v}^{*}\right)$ 를 출력한다.

$i_{p v}^{*}(t)=i_{s o l}(t)-\left[k_{p v}\left(v_{p v}^{*}(t)-v_{p v}(t)\right)+k_{i v} \int\left(v_{p v}^{*}(t)-v_{p v}(t)\right) d t\right]$

식 (8)을 식 (3)에 대입하고 라플라스 변환하면 다음과 같은 전달함수를 얻을 수 있으며, 제어기의 이득은 극배 치를 통해서 구할 수 있다. ${ }^{[8]}$

$$
\frac{v_{p v}(s)}{v_{p v}^{*}(s)}=\frac{\frac{K_{p v}}{C_{p v}} s+\frac{K_{i v}}{C_{p v}}}{s^{2}+\frac{K_{p v}}{C_{p v}} s+\frac{K_{i v}}{C_{p v}}}
$$

식 (10)과 (11)은 극배치 방식을 통해 얻은 전압제어 기 $\left(K_{p v}, K_{i v}\right)$ 와 전류제어기 $\left(K_{p i}, K_{i i}\right)$ 의 $\mathrm{PI}$ 게인 값에 관 련된 이득 선정 수식이다. PI 제어기의 이득 선정시 전 류제어기의 자연주파수 $\left(\omega_{n i}\right)$ 는 스위칭 주파수의 $1 / 10$ $1 / 20$, 전압제어기의 자연주파수 $\left(\omega_{n v}\right)$ 는 전류 제어기의 자 연주파수 $\left(\omega_{n c}\right)$ 의 $1 / 4 \sim 1 / 5$ 로 낮게 선정하여야 한다. 


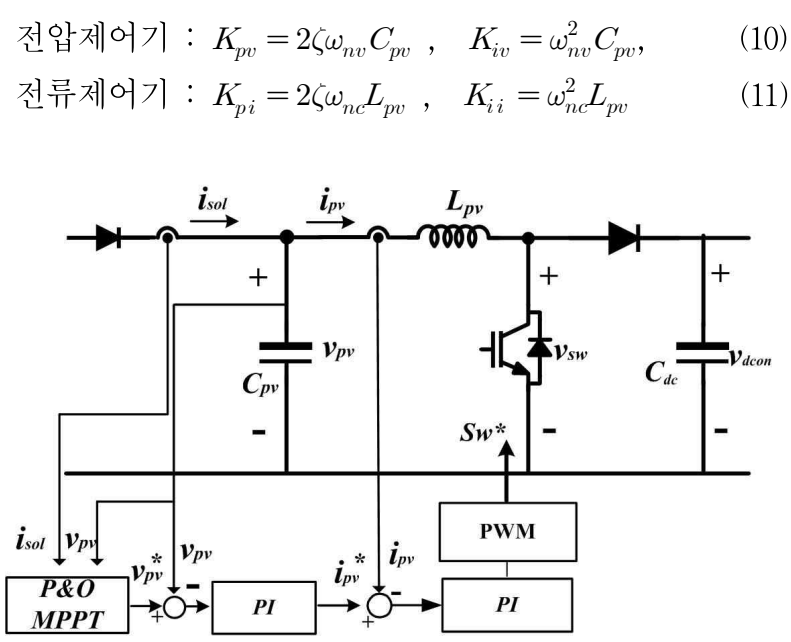

Fig. 2 Dual loop PI control of boost converter

\section{DCM영역에서 개선된 제어기}

일사량이 적으면 부스트 컨버터의 인덕터에 흐르는 전류가 불연속이 된다. 불연속 구간에서 제어 루프를 기 존의 2중 루프로 구성할 경우 제어기 출력에 오차가 발 생한다. 이로 인해 $\mathrm{MPPT}$ 출력 전압 $\left(v_{p v}^{*}\right)$ 을 정상적으로 추종하지 못하는 문제점이 발생하며, 이러한 오차의 원 인은 불연속모드에서 평균전류 제어를 할 경우에 인덕 터 전류가 0 이 되는 구간을 고려하지 않기 때문이다. 이 러한 문제점을 고려하여 전류제어기를 생략한 단일루프 제어기 및 연속 및 불연속모드에서 제어기의 구조를 바 꾸는 복합제어기를 채용하여 전술한 문제에 대한 대응 가능성을 제시한다.

\section{1 단일 루프 상태궤환 제어기}

단일루프 제어기는 2 중 루프 제어기와 달리 $\mathrm{PV}-\mathrm{array}$ 의 단자전압을 제어하기 위해 전류제어 루프를 사용하지 않고 그림 3과 같이 PV-array 단자전압의 기 준신호 $v_{p v}^{*}$ 와 실제 단자 전압 $v_{p v}$ 간의 오차를 이용하 여 직접 제어 신호를 만드는 방법이다. 단일루프 제어기 는 전류제어를 하지 않으므로 앞서 전술한 전류제어와 관련된 문제점을 피해갈 수 있는 장점을 갖는다. 단일루 프 제어를 기존의 PI 제어기로 구성할 경우 시스템의 전달함수는 식 (1)과 식 (3)에 의해 다음 식 (12)와 같이 상태 방정식으로 표현할 수 있으며,

$$
\left[\begin{array}{c}
\frac{d i_{p v}}{d t} \\
\frac{d v_{p v}}{d t}
\end{array}\right]=\left[\begin{array}{cc}
0 & \frac{1}{L_{p v}} \\
\frac{-1}{C_{p v}} & 0
\end{array}\right]\left[\begin{array}{c}
i_{p v} \\
v_{p v}
\end{array}\right]+\left[\begin{array}{c}
\frac{-1}{L_{p v}} \\
0
\end{array}\right] v_{s w}+\left[\begin{array}{c}
0 \\
1 \\
C_{p v}
\end{array}\right] i_{s o l}
$$

제어 입력 $v_{s w}$ 에 대한 제어변수 $v_{p v}$ 간의 전달함수는 다음과 같이 2 차식으로 표현된다.

$$
v_{p v}(s)=\frac{\frac{1}{L_{p v} C_{p v}}}{s^{2}+\frac{1}{L_{p v} C_{p v}}} v_{s w}^{*}(s)+\frac{\frac{1}{C_{p v}} s}{s^{2}+\frac{1}{L_{p v} C_{p v}}} i_{s o l}(s)
$$

만약 PI제어기를 이용하여 제어기를 구성할 경우 시 스템은 3 차식이 되어서 제어기의 이득 선정시 2 개의 이 득(비례이득 및 적분이득)을 이용하여 3 개의 극을 배치 하기는 어려우므로 제어이득 선정이 해석적으로 이루어 지기 어렵다.

본 논문에서는 정상상태의 오차를 제거하기 위해 그 림 3 와 같이 적분기를 채용한 상태궤한 제어기를 이용 하여 단일루프 제어기를 구성한다. 제어기의 구성은 식 (12)의 시스템의 상태 방정식에 적분제어요소를 포함하 여 시스템의 상태방정식을 다시 세우면 식 (14)와 같이 나타낼 수 있다.

$$
\begin{gathered}
{\left[\begin{array}{c}
d i_{p v} / d t \\
d v_{p v} / d t \\
d P / d t
\end{array}\right]=\left[\begin{array}{crr}
0 & 1 / L_{p v} & 0 \\
-1 / C_{p v} & 0 & 0 \\
0 & 1 & 0
\end{array}\right]\left[\begin{array}{c}
i_{p v} \\
v_{p v} \\
p
\end{array}\right]+\left[\begin{array}{c}
-1 / L_{p v} \\
0 \\
0
\end{array}\right] v_{s w}} \\
+\left[\begin{array}{cc}
0 & 0 \\
1 / C_{p v} & 0 \\
0 & -1
\end{array}\right]\left[\begin{array}{c}
i_{s o l} \\
v_{p v}^{*}
\end{array}\right]
\end{gathered}
$$

상태궤환 제어기의 제어규칙은 식 (15)과 같으며,

$$
v_{s w}^{*}=-\left[\begin{array}{lll}
g_{1} & g_{2} & g_{3}
\end{array}\right]\left[\begin{array}{c}
i_{p v} \\
v_{p v} \\
p
\end{array}\right]
$$

식 (5)와 (6)을 통해 $v_{s w}^{*}=v_{s w}$ 과 같이 두면, 식 (14)는 식 (16)과 같이 정리 할 수 있다.

$$
\left[\begin{array}{c}
\frac{d i_{p v}}{d t} \\
\frac{d v_{p v}}{d t} \\
\frac{d p}{d t}
\end{array}\right]=\left[\begin{array}{ccc}
\frac{g_{1}}{L_{p v}} & \frac{g_{2}+1}{L_{p v}} & \frac{g_{3}}{L_{p v}} \\
-\frac{1}{C_{p v}} & 0 & 0 \\
0 & 1 & 0
\end{array}\right]\left[\begin{array}{c}
i_{p v} \\
v_{p v} \\
p
\end{array}\right]+\left[\begin{array}{cc}
0 & 0 \\
\frac{1}{C_{p v}} & 0 \\
0 & -1
\end{array}\right]\left[\begin{array}{l}
i_{p v} \\
v_{p v}^{*}
\end{array}\right]
$$

시스템이 원하는 제어특성을 갖도록 특성 근을 배치하기 위 해 식 (16)의 특성방정식을 (17)과 같이 나타낼 수 있으며,

$$
\left|\begin{array}{ccc}
s-\frac{g_{1}}{L_{p v}} & \frac{-1-g_{2}}{L_{p v}} \frac{-g_{3}}{L_{p v}} \\
\frac{1}{C_{p v}} & s & 0 \\
0 & -1 & s
\end{array}\right|=s^{3}-\frac{g_{1}}{L_{p v}} s^{2}+\frac{1+g_{2}}{L_{p v} C_{p v}} s+\frac{g_{3}}{L_{p v} C_{p v}}=0
$$

최종적으로 식 (17)이 원하는 제어특성을 갖도록 설계한 특성 방정식 식 (18)과 동일한 형태가 되도록 궤환 이득 $\mathrm{g} 1, \mathrm{~g} 2, \mathrm{~g} 3$ 를 설정하면 된다. 


$$
\begin{array}{r}
\left(s+p_{1}+j p_{2}\right)\left(s+p_{1}-j p_{2}\right)\left(s+p_{3}\right)=s^{3}+\left(2 p_{1}+2 p_{3}\right) s^{2} \\
+\left(p_{1}^{2}+p_{2}^{2}+2 p_{1} p_{3}\right) s+\left(p_{1}^{2}+p_{2}^{2}\right) p_{3}=0
\end{array}
$$

여기서,

$p_{1}=\zeta \omega_{n}, \quad p_{2}=\omega_{n} \sqrt{1-\zeta^{2}}, p_{3}=k_{q} p_{1}$

$\omega_{n}=$ 자연주파수 $(\mathrm{rad} / \mathrm{sec}), \quad \zeta=$ 제동비 $(0.707)$

그러므로 상태궤환 제어기의 이득은 다음 식을 통해 용 이하게 설정할 수 있다.

$$
\begin{aligned}
& g_{1}=-2\left(p_{1}+p_{3}\right) L_{p v} \\
& g_{2}=\left[\left(p_{1}^{2}+p_{2}^{2}+2 p_{1} p_{3}\right) L_{p v} C_{p v}+1\right] \\
& g_{3}=\left(p_{1}^{2} p_{3}+p_{2}^{2} p_{3}\right) L_{p v} C_{p v}
\end{aligned}
$$

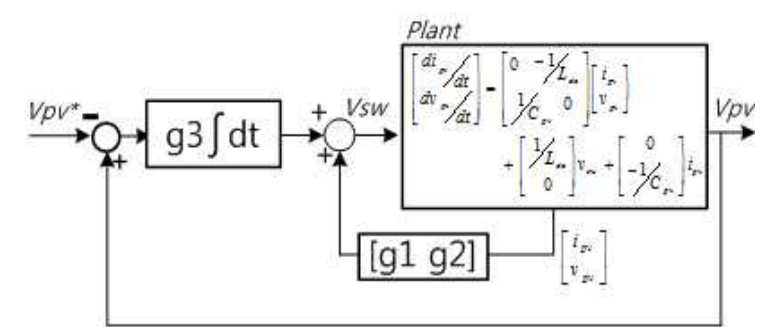

Fig. 3 Control block of state feedback controller

\section{2 복합 제어기}

복합제어기는 $\mathrm{DCM}$ 구간에서 인덕터 전류가 불연속 이 될 경우에 기존의 이중루프 제어기의 전류제어루프 를 대신하여 제안하는 방식을 사용해서 제어기를 변환 하는 방식이다. 이것은 전류가 연속일 경우와 불연속일 경우를 판단한 후 전류 제어규칙을 나누는 방식으로 제 어 방식은 다음과 같이 구할 수 있다.

PV-array의 출력이 낮아져서 전류가 불연속 모드에서 흐르게 되면 인덕터의 전류파형은 그림 4 와 같다. 그림 4 에서 한주기 스위칭 시간 $\left(T_{\mathrm{mod}}\right)$ 중 $T_{d i s}$ 를 제외한 $T_{o n \_d i s}$ 과 $T_{o f f}$ 구간 동안 인덕터 전류의 평균값 $\left(i_{p v_{-} c o n}\right)$ 은 다음 식(22)와 같이 구할 수 있다.

$$
i_{p v \_c o n}=\frac{v_{p v}}{2 L_{p v}} D_{d i s} T_{\bmod }
$$

여기서, $D_{d i s}$ : 불연속모드에서 시비율

$$
T_{\mathrm{mod}}=T_{\text {on_dis }}+T_{\text {off }}+T_{\text {dis }}: \text { 스위칭 주기 }
$$

또한 $T_{o n \_d i s}$ 과 $T_{o f f}$ 구간 동안 인덕터 전류의 평균 변화 량은 영이 되므로 다음의 관계식을 만족하며,

$$
\frac{v_{p v} D_{d i s} T_{\mathrm{mod}}}{L_{p v}}=\frac{\left(v_{d c o n}-v_{p v}\right) T_{o f f}}{L_{p v}}
$$

식(23)을 이용하면 $T_{o f f}$ 는 다음과 같이 구할 수 있다.

$$
T_{\text {off }}=\frac{v_{p v} D_{d i s} T_{\mathrm{mod}}}{v_{\text {doon }}-v_{p v}}
$$

식(22)와 식(24)를 이용하여 불연속 모드에서 스위칭 한 주기 동안 실제 인덕터의 평균전류 $\left(\overline{i_{p v-d i s}}\right)$ 를 다음 식 (25)와 같이 표현할 수 있으며,

$\overline{i_{p v_{-} d i s}}=\frac{T_{o n \_d i s}+T_{o f f}}{T_{\bmod }} i_{p v_{-c o n}}=\frac{v_{p v} v_{d c o n} T_{\bmod }}{2 L_{p v}\left(v_{d c o n}-v_{p v}\right)} D_{d i s}^{2}$

불연속 모드에서 인덕터의 평균전류 $\overline{i_{p v \_d i s}}$ 가 결정되면 시비율 $\left(D_{d i s}\right)$ 은 다음 식 (26)과 같이 계산된다.

$$
D_{d i s}=\sqrt{\overline{i_{p v \_d i s}} \frac{2 L_{p v}\left(v_{d c o n}-v_{p v}\right)}{v_{p v} v_{d c o n} T_{\text {mod }}}}
$$

이중제어루프에서 전압제어에 의해서 만들어진 기준신 호 $i_{p v}^{*}$ 는 식 (25)의 $\overline{i_{p v-d i s}}$ 와 동일한 의미를 가지므로 불 연속모드에서 시비율은 식 (27)과 다시 쓸 수 있다.

$$
D_{d i s}=\sqrt{i_{p v}^{*} \frac{2 L_{p v}\left(v_{d c o n}-v_{p v}\right)}{v_{p v} v_{d c o n} T_{\bmod }}}
$$

여기서 $i_{p v}^{*}(t)=\left[k_{p v}\left(v_{p v}^{*}(t)-v_{p v}(t)\right)+k_{i v} \int\left(v_{p v}^{*}(t)-v_{p v}(t)\right) d t\right]$

불연속모드에서 전류 제어식을 식(28)과 같이 구성하면,

$$
v_{s w}^{*}(t) \_d i s=\left(1-D_{d i s}\right) v_{d c o n}
$$

최종적으로 복합제어기의 전류 제어규칙은 다음 식(29) 와 같이 정리할 수 있다.

$$
\begin{aligned}
v_{s w}^{*}(t)=v_{s w}^{*}(t) \_c o n \times(1-\bmod e) & \\
& +v_{s w}^{*}(t) \_d i s \times \bmod e
\end{aligned}
$$

여기서

$$
\begin{aligned}
v_{s w}^{*}(t) \_c o n & =v_{p v}-\left[k_{p i}\left(i_{p v}^{*}(t)-i_{p v}(t)\right)+k_{i i} \int\left(i_{p v}^{*}(t)-i_{p v}(t)\right) d t\right] \\
\text { if mode } & =0 \quad: \quad \text { 연속모드 } \\
\text { if mode } & =1 \quad: \text { 불연속모드 }
\end{aligned}
$$

식 (29)에서 mode는 연속과 불연속 모드를 판별하는 신호로 이를 구하기 위해서는 $T_{o n \_d i s}$ 과 $T_{o f f}$ 의 시간 정 보가 필요하다. 스위치 차단 후 전류가 흐르는 시간 $T_{o f f}$ 는 식 (24)와 같으며, $T_{o n \_d i s}$ 는 식 (26)에서 구한 $D_{d i s}$ 와 $T_{\bmod }$ 를 이용하면 다음과 같이 구할 수 있다.

$$
T_{o n \_d i s}=T_{\text {mod }} D_{d i s}
$$




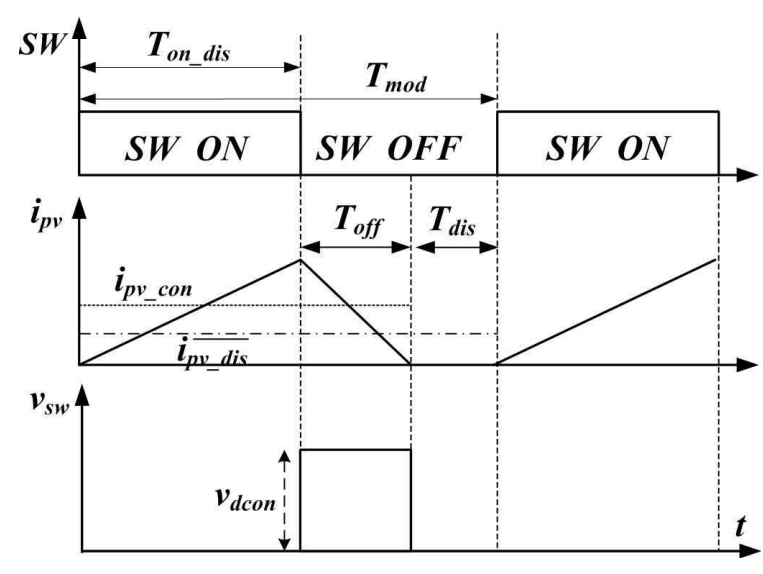

Fig. 4 Inductor current in DCM

그러므로 복합 제어기에서 식 (29)의 모드 판별 신호 (mode)를 만드는 방법은 식 (31)과 같이 나타낼 수 있다. 불연속 모드에서는 스위치 온 시간과 스위치가 꺼진 후 전류가 흐르는 시간의 합이 스위칭 주기 $\left(T_{\bmod }\right)$ 보다 작 거나 같아야 하므로 다음과 같이 불연속 모드에서의 운 전 조건을 표현할 수 있다.

$$
\begin{aligned}
& T_{o n}+T_{\text {off }}<T_{\text {mod }} \rightarrow \bmod e=1 \\
& T_{\text {on }}+T_{\text {off }}=T_{\text {mod }} \rightarrow \bmod e=0
\end{aligned}
$$

\section{4. 시뮬레이션 및 실험결과}

\section{1 시뮬레이션 결과}

실험 및 시뮬레이션을 위해 표 1 과 같이 시스템의 전 기적 사양을 결정하였다. 정격은 $3 \mathrm{~kW}$ 이며, 시뮬레이션 은 PSIM 9.0을 이용하여 검증하였다. 그림 5는 PSIM으 로 구성한 시뮬레이션 회로를 나타내며, 그림과 같이 부 스트 컨버터의 입력측은 시뮬레이션 툴에서 제공하는 PV-array를 사용하며, 출력 부하는 단상 계통 연계형 인버터를 이용하여 계통과 연계하였다. 실험 및 시뮬레 이션을 통해 부스트 컨버터가 불연속 구간에서 동작할 때 앞서 전술한 3 가지 제어기의 특성을 확인하였다.

그림 6은 PV-array의 출력이 $130 \mathrm{~W}$ 와 $270 \mathrm{~W}$ 일 때 상 태궤환 제어기의 출력 특성을 나타낸다. 이때 부스트-

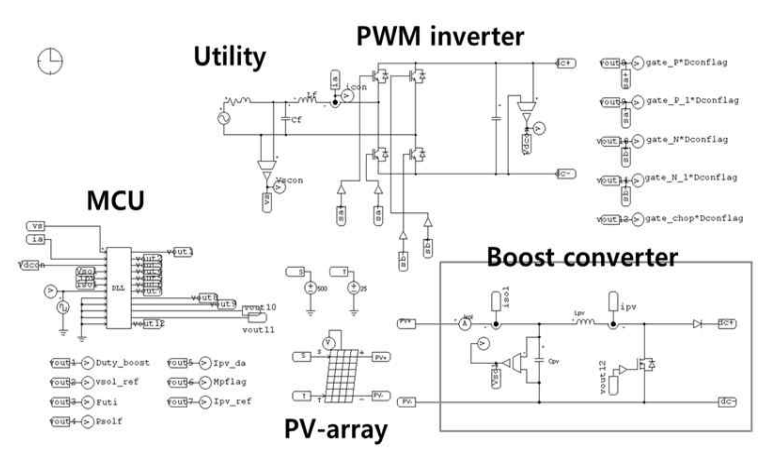

Fig. 5 Simulation circuit using PSIM
Table 1 Specifications of the Boost converter

\begin{tabular}{|c|l|c||c|}
\hline \multicolumn{2}{|c|}{ Parameter } & Value & Unit \\
\hline \hline \multirow{4}{*}{$\begin{array}{c}\text { System } \\
\text { specifications }\end{array}$} & PV-array & 3 & $\mathrm{~kW}$ \\
\cline { 2 - 4 } & Input Voltage & 280 & $\mathrm{Vdc}$ \\
\cline { 2 - 4 } & Inductor & 2 & $\mathrm{mH}$ \\
\cline { 2 - 4 } & Capacitor & 560 & $\mathrm{uF}$ \\
\cline { 2 - 4 } & DC_link Cap & 2240 & $\mathrm{uF}$ \\
\cline { 2 - 4 } & Frequency & 10 & $\mathrm{kHz}$ \\
\cline { 2 - 4 } & Output Voltage & 360 & $\mathrm{~V}$ \\
\hline \multirow{4}{*}{$\begin{array}{c}\text { PI controller } \\
\text { and }\end{array}$} & Voltage P-gain & 0.24 & $\mathrm{eq}(10)$ \\
\cline { 2 - 4 } Hybrid controller & Voltage I-gain & 55.26 & $\mathrm{eq}(10)$ \\
\cline { 2 - 4 } & Current P-gain & 7.10 & $\mathrm{eq}(11)$ \\
\cline { 2 - 4 } & Current I-gain & 12632.5 & $\mathrm{eq}(11)$ \\
\hline \multirow{2}{*}{$\begin{array}{c}\text { State-feedback } \\
\text { controller }\end{array}$} & $\mathrm{g} 1$ & -12.645 & $\mathrm{eq}(19)$ \\
\cline { 2 - 4 } & $\mathrm{g} 2$ & 1.583 & $\mathrm{eq}(20)$ \\
\cline { 2 - 4 } & $\mathrm{g} 3$ & 1720.5 & $\mathrm{eq}(21)$ \\
\hline
\end{tabular}

컨버터의 입력 전압제어만을 수행하기 때문에 불연속 전류에 의한 영향을 받지 않는 특성을 보이며, MPPT 출력전압(reference voltage)을 부스트 컨버터의 입력전 압(Input voltage)이 오차범위 $\pm 0.25 \mathrm{~V}$ 이내로 추종하고 있음을 시뮬레이션을 통해 확인 할 수 있다.

그림 7은 제안하는 복합제어방식의 시뮬레이션 파형 으로 PV-array의 출력이 각각 $130 \mathrm{~W}$ 와 $270 \mathrm{~W}$ 일 때 기 존의 PI 제어방식과 복합제어방식의 비교파형을 보여준 다. 그림 $7(\mathrm{a})$ 의 경우 PV-array의 출력이 낮아서 인덕터 전류의 불연속 구간이 길어지게 되어 전압제어기의 출 력인 전류 지령치 $\left(I_{p v_{-} r e f}\right)$ 와 실제 전류 $\left(I_{s o l}\right)$ 사이에 오차가

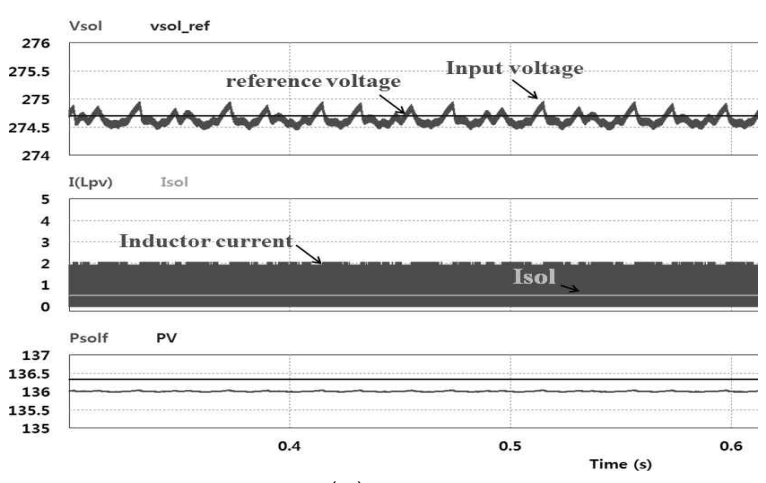

(a) $130 \mathrm{~W}$

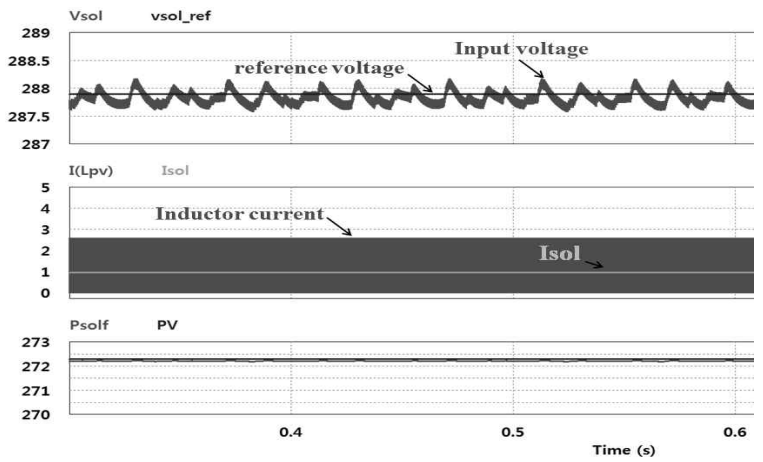

(b) $270 \mathrm{~W}$

Fig. 6 State feedback controller 


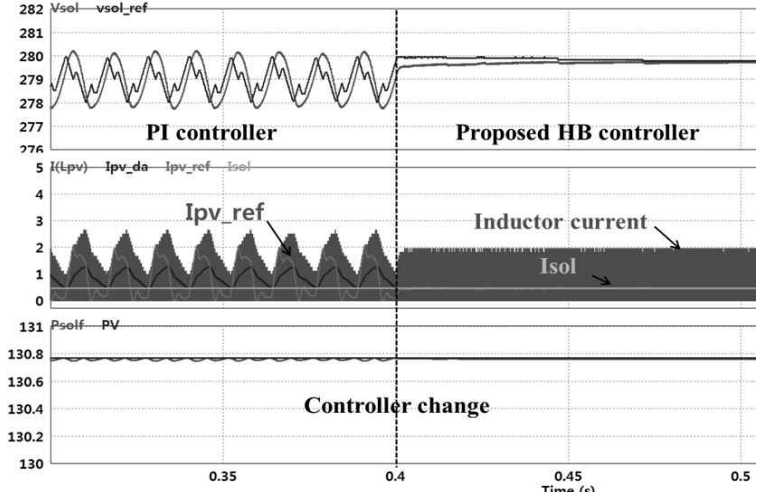

(a) $130 \mathrm{~W}$

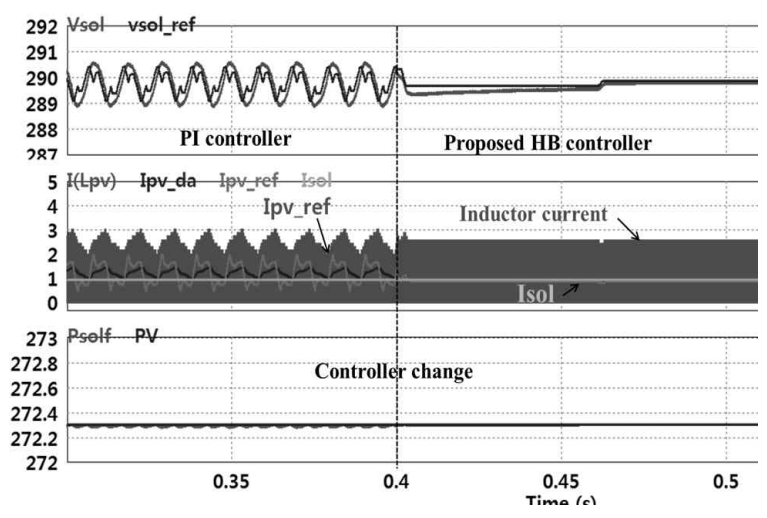

(b) $270 \mathrm{~W}$

Fig. 7 Proposed hybrid controller

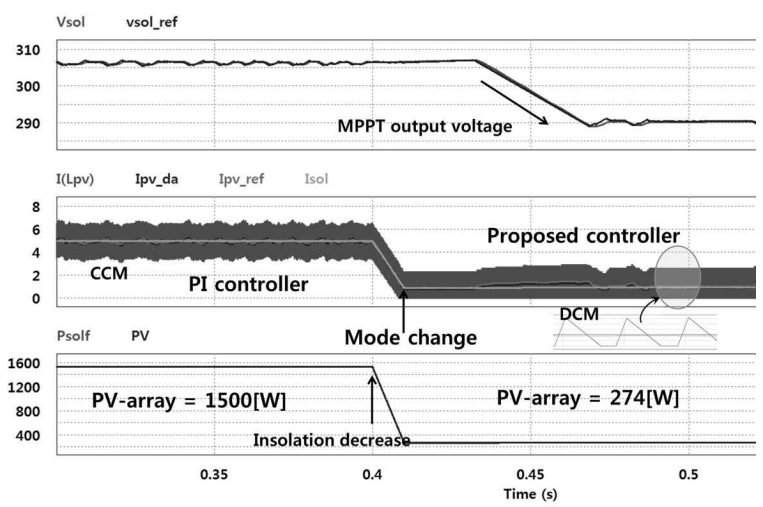

(a) Mode change

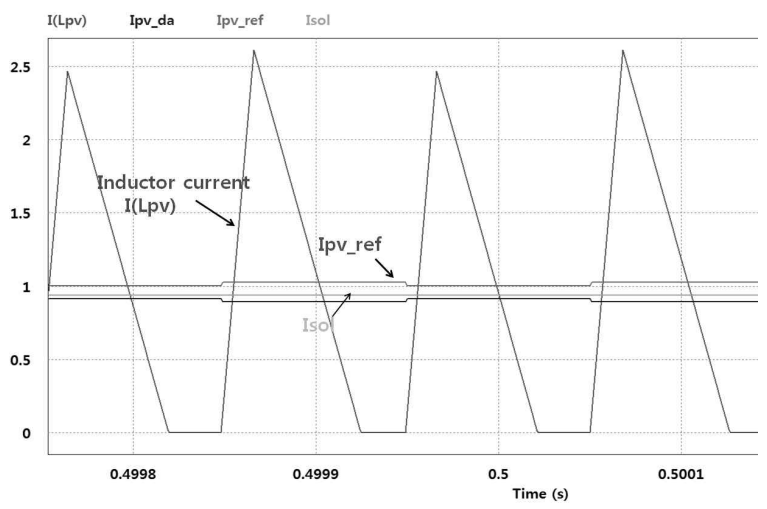

(b) The current of boost converter

Fig. 8 Using hybrid controller in PV system
커져 MPPT출력 전압을 정확히 추종하지 못하고 $\pm 1 \mathrm{~V}$ 의 오차를 가지고 진동을 하면서 추종하고 있음을 확인할 수 있다. 이때 $0.4 \mathrm{~s}$ 에서 제어방식을 제안하는 복합제어 로 변경할 경우 불연속 구간에서 $\mathrm{PV}$ 전류 $\left(I_{s o l}\right)$ 가 전압제 어기의 출력인 전류 지령치 $\left(I_{p v-r e f}\right)$ 를 정확하게 추종하는 것을 확인할 수 있으며, 전압제어 또한 진동 없이 안정 하게 제어됨을 확인할 수 있다. 또한 그림 7(b)의 경우 는 PV-array의 출력이 $270 \mathrm{~W}$ 로 그림 7(a)보다 증가하여 인덕터 전류의 불연속 구간이 줄어들게 되어 출력 전류 와 지령 전류사이의 오차가 감소하게 된다. 이로 인해 전압과 전류의 진동은 $\pm 0.75 \mathrm{~V}$ 로 줄어들지만 여전히 제 어가 부정확하게 이루어진다. 하지만 제안하는 복합제어 방식으로 $0.4 \mathrm{~s}$ 에 제어 방식을 변경하면 전압과 전류에 진동이 제거되며, 정확한 제어가 이루어짐을 시뮬레이션 을 통해 확인할 수 있다. 제안하는 두 가지 방식 중 복 합제어 방식이 정상상태에서 오차가 작아 정상상태 특 성이 우수함을 확인 할 수 있다.

그림 8은 제안하는 복합제어 방식을 사용한 시뮬레이 션 파형으로 그림 8(a)는 PV-array의 출력이 $1500 \mathrm{~W}$ 에 서 $274 \mathrm{~W}$ 로 변화할 때의 부스트 컨버터의 각 부분의 출 력 특성을 보여준다. PV-array의 출력이 감소하여 인덕 터의 전류가 불연속이 되었을 때 제어 방식이 바뀌어 불연속 전류에서도 정확한 전류 제어와 전압제어가 이 루어지는 것을 시뮬레이션을 통해 확인할 수 있다. 또한 제어 방식이 변경되었을 때의 전류 파형을 확대 하면 그림 $8(\mathrm{~b})$ 와 같이 전압제어기의 출력인 전류레퍼런스 $\left(I_{p v \_r e f}\right)$ 를 $\mathrm{PV}-\mathrm{array}$ 출력전류 $\left(I_{s o l}\right)$ 와 인덕터 전류 $\left(I_{L p v}\right)$ 가 정확히 추종하고 있음을 확인할 수 있다.

\section{2 실험결과}

실험적인 분석 및 검증을 위해 그림 11 과 같이 실험 세트를 제작하였다. 입력전원은 PV 시뮬레이터를 사용 하였으며, 부스트 컨버터의 출력은 계통 연계형 인버터 와 연계 구성하여 발전전력을 계통으로 전송하며, 제어 를 위한 컨트롤러는 TI사의 DSP TMS320F28335를 사 용하였다. 스위치는 정격전압 $600 \mathrm{~V}$, 정격전류 $50 \mathrm{~A}$ 의 IGBT 소자를 사용하였으며, 인덕터는 $2 \mathrm{mH}$, 입력 커패 시터는 $560 \mathrm{uF}$ 을 사용하였다. 실험 세트의 전체적인 파 라미터는 표 1 과 같으며, 제어기의 게인 값은 $\mathrm{AD}$ (Analog to Digital)에 입력되는 노이즈로 인해 시뮬 레이션에서 얻은 값에서 약간의 수정과정을 거쳤다.

그림 9(a)와 (b)는 상태궤환 제어기를 사용할 경우의 출력 특성을 나타내며, 비교를 위해 PI제어로 제어를 수 행하다가 중간에서 제어방식을 변경하였다. 컨버터의 입 력전압은 $280 \mathrm{~V}$ 로 제어되며, (a)의 경우 $100 \mathrm{~W},(\mathrm{~b})$ 의 경 우는 $300 \mathrm{~W}$ 의 출력에서 동작되며, 모두 불연속 구간에서 실험이 진행되었다. 시뮬레이션과 같이 $\mathrm{PI}$ 제어의 경우 낮은 전력일수록 불연속 구간이 커져 출력 전압에 진동 이 많이 발생하며, 이것을 상태궤환 제어로 제어기를 바 
꿀 경우 출력전압에 진동이 없이 정확한 전압제어가 이 루어지는 것을 실험을 통해 확인할 수 있다.

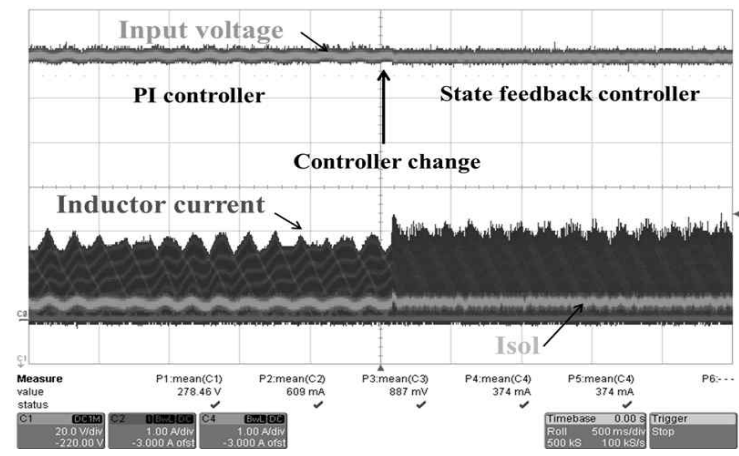

(a) Power $=100 \mathrm{~W}$

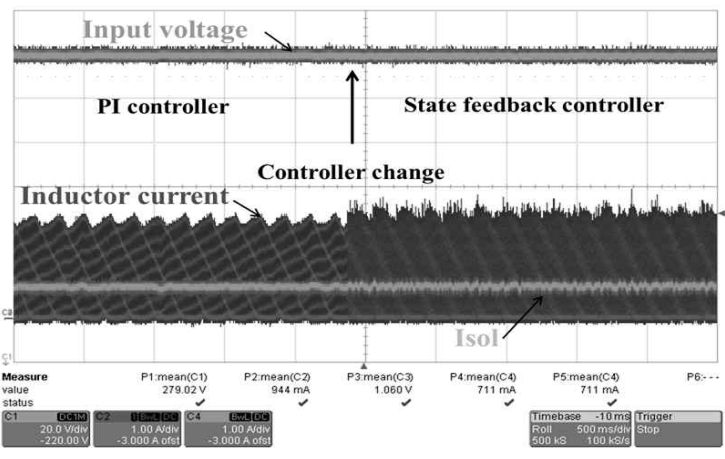

(b) Power $=300 \mathrm{~W}$

Fig. 9 Using State feedback controller

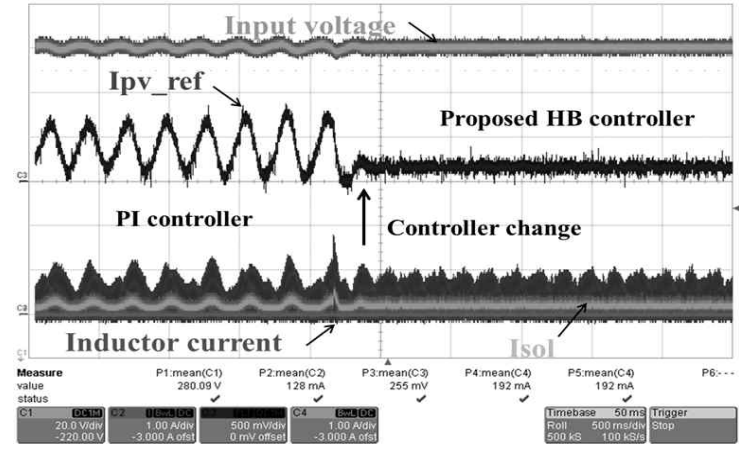

(a) Power $=100 \mathrm{~W}$

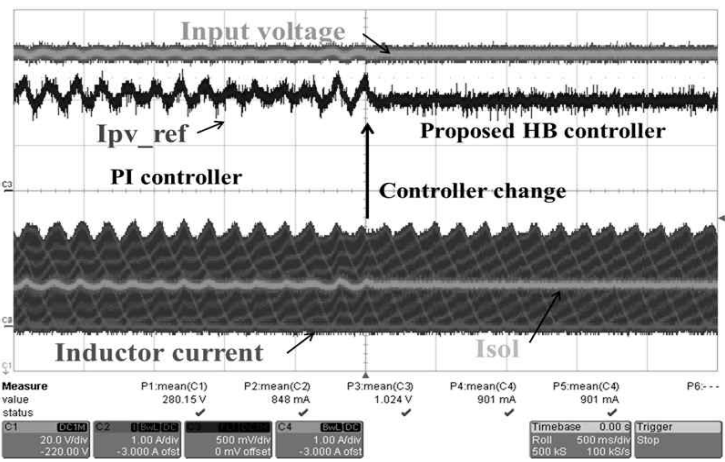

(b) Power $=300 \mathrm{~W}$

Fig. 10 Using proposed hybrid controller

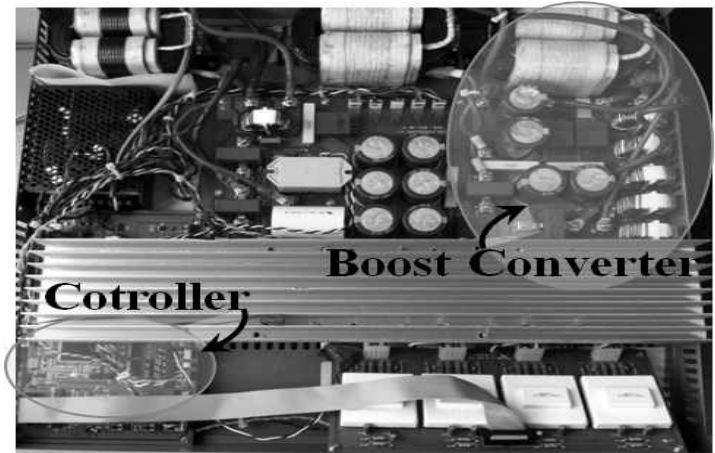

Fig. 11 Hardware of 3kW PV system

그림 10은 복합제어 방식을 사용할 경우를 보여주며, 실험 방식은 그림 9 와 같다. 시뮬레이션과 같이 불연속 구간에서 기존 $\mathrm{PI}$ 제어기를 사용할 경우에 전압제어기의 출력 전류 지령치 $\left(I_{p v_{-} r e f}\right)$ 에 진동이 발생하고, 정확한 전 류제어를 수행하지 못한다. 하지만 제안하는 방식으로 제어방식을 변경할 경우 그림과 같이 전류 지령에 진동 이 없어지며, 정확한 입력전압의 제어가 이루어지는 것 을 실험을 통해 확인할 수 있다.

\section{5. 결 론}

본 논문은 계통 연계형 태양광 발전시스템에서 사용 되는 부스트 컨버터가 불연속 전류구간에서 운전 될 경 우 입력 제어 특성에 관한 연구를 수행하였다.

일사량이 감소할 경우 발생하는 불연속 구간에서 기존 의 PI 전류제어 방식으로는 전류 측정오차로 인하여 정 확한 제어가 수행되지 않는다. 이로 인해 정확한 입력 전압제어가 이루어지지 않음을 시뮬레이션 및 실험을 통해 확인하고 개선된 제어방식을 제시하였다.

제시하는 방식은 전압제어만을 사용하는 상태궤환 제 어기와 내부 전류제어방식을 변경하는 복합제어 방식으 로 두 방식 모두 안정된 입력 전압제어를 수행하는 것 을 시뮬레이션 및 실험을 통해 확인하였으며, 제안하는 제어 방식은 향후 불연속 구간에 운전되는 다양한 토폴 로지에 적용이 가능할 것으로 판단된다.

본 연구는 중소기업청의 중소기업 산학연협력사 업 사업계획 “일반과제"의 일환으로 수행되었습니 다. (No.C0041237)

\section{References}

[1] Gyu-Ha Choe, Bayasgalan D, Young Jin Lee, "Characteristics Analysis of RPV and AFD for Anti-Islanding in Active Method," Journal of KIPE, Vol. 14, No. 2, pp. 
160-167, Apr. 2009.

[2] J. M. Carrasco, L. G. Franquelo, J. T. Bialasiewicz, E. Galvan, R. C. P. Guisado, M. A. M. Prats, J. I. Leon, and N. Moreno-Alfonso, "Power-electronic systems for the grid integration of renewable energy sources: A survey," IEEE Trans. Ind. Electron., Vol 53, No. 4, pp. 1002-1016, Jun. 2006.

[3] F. Blaabjerg, R. Teodorescu, M. Liserre, and A. Timbus. "Overview of control and grid synchronization for distributed power generation system," IEEE Trans. Ind. Electron, Vol. 53, No. 5, pp. 1398-1409, Oct. 2006.

[4] Fermia, N., Petrone, G. "A Technique for Improving P\&O MPPT Performances of Double-Stage Grid-Connected Photovoltaic Systems," Industrial Electronics, IEEE Transactions on, pp. 4473-4482, Nov. 2009 .

[5] B. M Hasaneen, Adel A. Elbaset "Design and Simulation of DC/DC Boost Converter," Proceeding of the IEEE, pp. 335-340, 2008.

[6] Seunggoo Lee, Youngroc Kim, Hanju Cha "New current gain feedforward compensation for improving MPPT efficiency," in Proceedings of KIPE Power Electronics Annual Conference, pp. 91-92, Jul. 2011.

[7] Young Jin Lee, Donh Hwa Han, Gyu Ha Choe "A Study on the Grid Connected Battery Charge System," in Proceedings of KIPE Power Electronics Annual Conference, pp. 101-103, Nov. 2010.

[8] K. J. Astrom, Tore Hagglund, "Automatic Tuning of PID Controllers," Instrument Society of America, 1988

[9] Byeng Joo Byen, H.U. Seo, Y.J. Lee, G.H. Choe, "Single Loop Algorithm Using State Feedback Controller for Boost Converter of PV System," in Proceedings of KIPE Power Electronics Annual Conference, pp. 105-106, Nov. 2012

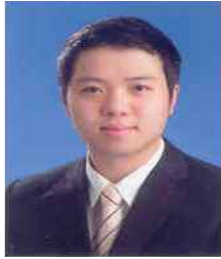

이영진 (李永鎭)

1983년 2월 26일생. 2008년 건국대 전기공 학과 졸업. 2010년 동 대학원 전기공학과 졸업(석사). 2010년 현재 동 대학원 박사과 정.

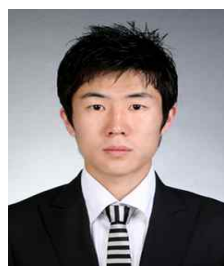

\section{한동화(韓棟華)}

1982년 11월 17일생. 2008년 건국대 전기공 학과 졸업. 2010년 동 대학원 전기공학과 졸업(석사). 2010년 현재 동 대학원 박사과 정.

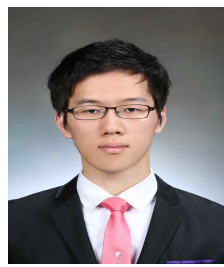

\section{변 병 주(邊秉柱)}

1988년 12월 10일생. 2011년 건국대 전기공 학과 졸업. 2011년 현재 동 대학원 석박통 합과정.

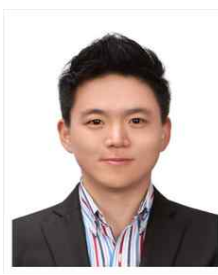

\section{최 중묵 (崔重默)}

1983년 1월 1일생. 2008년 건국대 전기공학과 졸업. 2010년 동 대학원 전기공학과 졸업(석 사). 2010년 2011년 LS산전 중앙연구소. 2011 년 현재 동 대학원 박사과정.

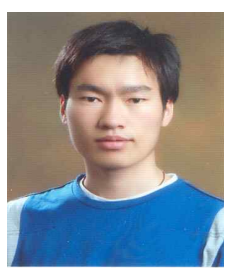

\section{Dugarjav Bayasgalan}

1982년 7월 3일생. 2005년 몽골 과학기술대 기계전자학과 졸업. 2008년 건국대 공대 대 학원 전기공학과 졸업(석사). 2013년 동 대 학원 전기공학과 졸업(박사).

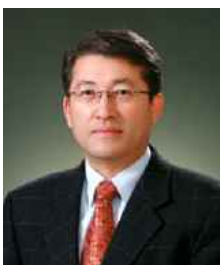

\section{최규하(崔圭夏)}

1955년 7월 24일생. 1978년 서울대 공대 전 기공학과 졸업. 1980년 동 대학원 전기공학 과 졸업(석사). 1986년 동 대학원 전기공학 과 졸업(공박). 1987년 1988년 미국 오레곤 주립대 전기공학과 Psot-Doc. 1998년 1999 년 버지니아주립대 교환방문교수. 1997년 1998년 건국대 연구 처 처장. 1996년 현재 건국대 산업기술연구원 인버터제어기술 연구센터 소장. 1999년 현재 건국대 부설전력전자신기술연구센 터 소장. 2002년 2004년 건국대 교무처 처장. 1996년 현재 전 기안전공사 전기안전기술 자문위원. 2007년 2008년 당 학회 회 장역임. 현재 건국대 전기공학과 교수 및 건국대 부총장. 